\title{
Peroxisome Proliferator-Activated Receptor (PPAR): Balance for Survival in Parasitic Infections
}

\author{
Marion M. Chan, ${ }^{1}$ Kyle W. Evans, ${ }^{1}$ Andrea R. Moore, ${ }^{1}$ and Dunne Fong ${ }^{2}$ \\ ${ }^{1}$ Department of Microbiology and Immunology, School of Medicine, Temple University, 3400 North Broad Street, \\ Philadelphia, PA 19140, USA \\ ${ }^{2}$ Department of Cell Biology and Neuroscience, Rutgers, The State University of New Jersey, \\ Piscataway, NJ 08854, USA
}

Correspondence should be addressed to Marion M. Chan, marion.chan@temple.edu and Dunne Fong, fong@biology.rutgers.edu

Received 31 August 2009; Accepted 10 November 2009

Academic Editor: Luis I. Terrazas

Copyright (C) 2010 Marion M. Chan et al. This is an open access article distributed under the Creative Commons Attribution License, which permits unrestricted use, distribution, and reproduction in any medium, provided the original work is properly cited.

\begin{abstract}
Parasitic infections induce a magnitude of host responses. At the opposite ends of the spectrum are those that ensure the host's needs to eliminate the invaders and to minimize damage to its own tissues. This review analyzes how parasites would manipulate immunity by activating the immunosuppressive nuclear factor, peroxisome proliferator-activated receptors (PPARs) with type 2 cytokines and free fatty acids from arachidonic acid metabolism. PPARs limit the action of type 1 immunity, in which classically activated macrophages act through the production of proinflammatory signals, to spare the parasites. They also favor the development of alternately activated macrophages which control inflammation so the host would not be destroyed. Possibly, the nuclear factors hold a pivotal role in the establishment of chronic infection by delicately balancing the pro- and anti-inflammatory signaling mechanisms and their ligands may be used as combination therapeutics to limit host pathology.
\end{abstract}

\section{Introduction}

Infection is the outcome of a contest between a pathogen and its host. The host responds to an invasion by activation of inflammation and launching of innate and specific immunity. The goal is to eliminate the pathogen. On the other hand, the pathogen seeks to proliferate and spread to a new host when one is destroyed. The task of parasites is particularly challenging because they need to strike a balance between their own and the host's defense so they can continue to take advantage of the host to survive. It is wellknown that parasites are mostly immunosuppressive; the mechanisms they use to penetrate immune defense may be unique or shared by many species. Among the many means of surviving host immunity, one that has recently emerged is the activation of PPAR. This strategy promotes parasite survival by increasing energy metabolism and suppressing inflammation to allow invasion and avoid host destruction. The goal of this article is to review our current knowledge on how activation of PPAR may affect the survival of parasites and their hosts.

\section{Peroxisome Proliferator-Activated Receptors}

PPARs are ligand-activated transcription factors of the nuclear hormone receptor superfamily that consists of over 48 transcription factors. There are three PPAR isoforms$\operatorname{PPAR} \alpha, \operatorname{PPAR} \beta / \delta$, and PPAR $\gamma$ also known as NR1C1, $\mathrm{NR} 1 \mathrm{C} 2$, and NR1C3, respectively, and they differ in tissue distribution and function $[1,2]$. PPAR $\alpha$ is expressed in a variety of tissues involved in fatty acid oxidation, mainly the hepatocytes, cardiac myocytes, and proximal tubular epithelial cells of the kidney. It was so named because it was found to induce proliferation of peroxisomes in rodent livers (but not humans) when activated. Whereas PPAR $\alpha$ has limited tissue expression, PPAR $\beta / \delta$ is expressed ubiquitously and plays an important role in energy homeostasis. PPAR $\gamma$ is a master regulator of adipocyte differentiation and is an important determinant of insulin sensitivity. Two subtypes are known in mice and four in humans $[3,4]$. They are most highly expressed in adipose tissue, the colonic mucosal epithelium, and cells of the immune system. 


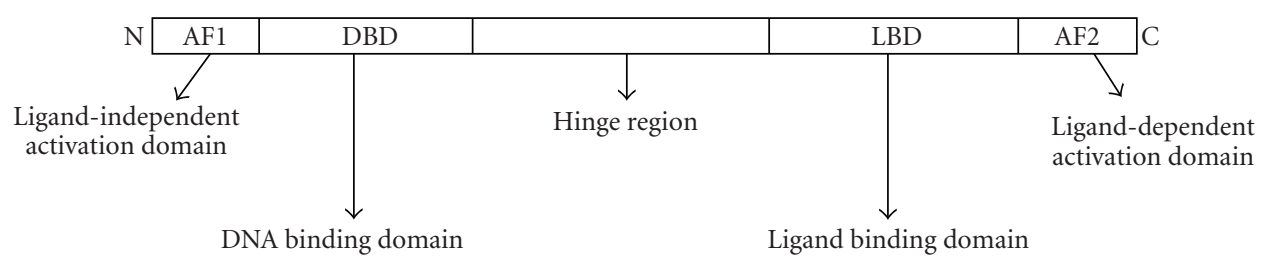

FIGURe 1: Domain structure of PPARs. PPARs contain the following functional regions: a N-terminal domain with AF-1 domain (ligandindependent activation domain), a DNA binding domain (DBD) with two zinc fingers, a hinge region, and a C-terminal ligand binding domain (LBD) and AF-2 domain (ligand-dependent activation domain).

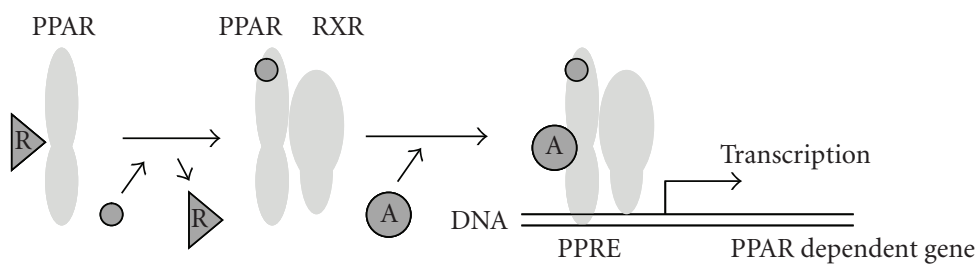

(a)

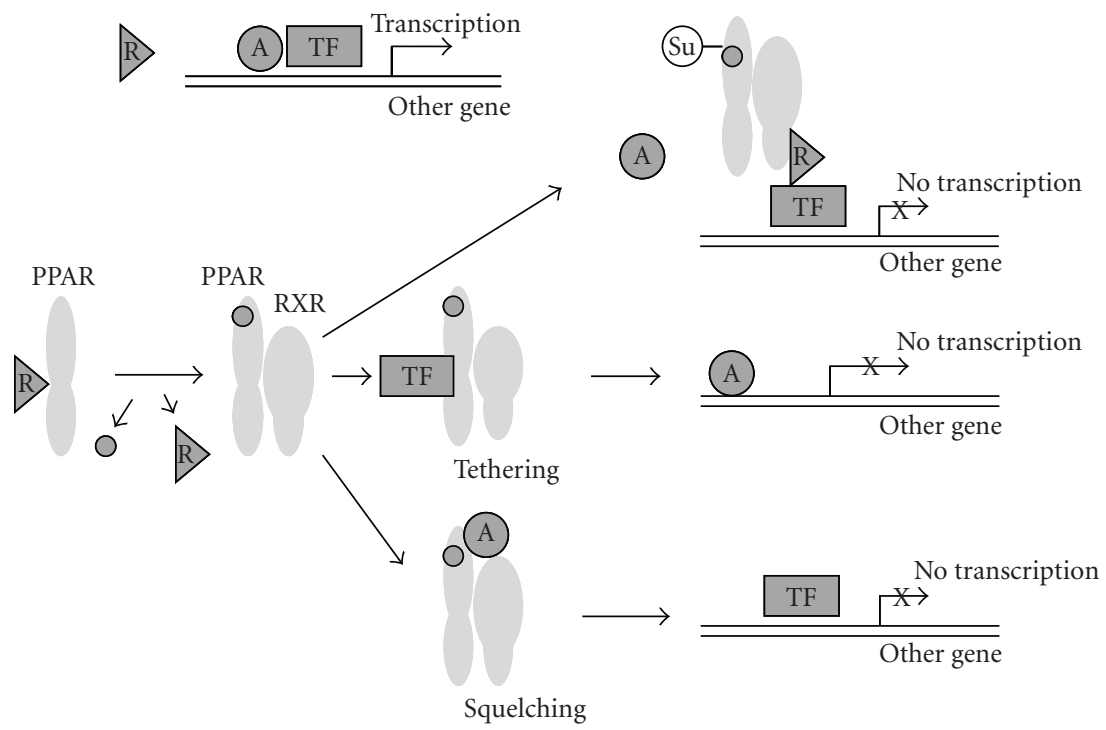

(b)

FIGURE 2: General Schematics of PPAR function. General mechanisms of (a) genomic expression and (b) transrepression of gene expression by PPAR/RXR heterodimers. In (a), upon ligand binding PPAR associates with RXR and coactivator to turn on target genes via the PPAR response element (PPRE). In (b), blocking the dissociation of corepressor from transcription factor at the gene locus, association of transcription factor to PPAR/RXR by tethering, and association of coactivator with PPAR/RXR by squelching, inhibit the transcription of different genes. $\mathrm{R}$ = corepressors, filled circle = ligand, $\mathrm{A}=$ coactivators, $\mathrm{TF}=$ transcription factor. Su indicates modulation by small regulatory protein (sumoylation).

Structurally, PPARs have a DNA-binding domain, a ligand-binding domain, two activation function sites, as well as sites for phosphorylation and dimerization (Figure 1) $[2,5,6]$. Activation is primarily ligand dependent and heterodimerization with the retinoid $\mathrm{X}$ receptor (RXR) is necessary. Figure 2 shows a simplified scheme of PPAR function in genomic expression and transrepression. Endogenous ligands for the PPARs include free fatty acids. Eicosanoids and 9-cis-retinoic acid bind to the PPAR-RXR complex to cause conformational changes that dissociate the corepressor, setting the complex free to interact genomically with the
PPAR response element (PPRE), AGGTCANAGGTCA (two AGGTCAs separated by one nucleotide), located at the $5^{\prime}$ end of target genes (Figure 2(a)).

In contrast to genomic binding, PPARs also interact with other transcription factors through nongenomic transrepression. In this process, they inhibit transcription by preventing dissociation of corepressors or sequestering the co-activators necessary for the binding of the transcription factor to DNA $[7,8]$. Both PPAR $\alpha$ and $\gamma$ suppress inflammation and immunity by inhibiting the activation of major transcription factors that control the expression of cytokines. 
For example, PPAR $\alpha$ can tether on to the nuclear factorkappa $\mathrm{B}(\mathrm{NF} \kappa \mathrm{B})$ and prevent its transcription of interleukin6 (IL-6); sumoylated PPAR $\gamma$ can bind nuclear receptor corepressor (NCoR)-histone deacetylase 3 (HDAC3) complex to prevent it from dissociating from $\mathrm{NF} \kappa \mathrm{B}$ and thus preventing the gene expression of inducible nitric oxide synthase (iNOS) (Figure 2(b)) [9].

\section{Immune Defense against Parasitic Infections}

Many parasitic infections are controlled by cell-mediated immunity. For host protection, controlling parasite growth relies on a type 1 response with activation of the classically activated macrophages (caMac, also known as M1), Thelper1 (Th1), Th17, the production of proinflammatory mediators, such as IL- $1 \beta$, IL- 6 , tumor necrosis factor $\alpha$ (TNF $\alpha$ ), IL-12, IL-23, IL-27, interferon $\gamma($ IFN $\gamma)$, and generation of nitric oxide. On the contrary, a type 2 response with Th2 cells that produce IL-4 and IL-13 would render the host susceptible to infection. These cytokines activate $\operatorname{PPAR} \gamma$, which suppresses production of proinflammatory cytokines, are critical for the formation, activation, and maintenance of a subpopulation of macrophages, alternatively activated macrophages (aaMac, also referred to as M2) [10]. AaMac are found during parasitic infections and have been associated with downregulation of type 1 immunity as well as the survival of both protozoa and helminthes. This emerging subject of investigation has been reviewed recently by Reyes and Terrazas [11] and other investigators [12, 13]. AaMac not only inhibit $\mathrm{T}$ cell proliferation, but also promote resolution of inflammation and fibrogenesis. They actively express a set of genes enabling them to regulate anti-inflammatory processes, induce tolerance and wound healing. These antiinflammatory regulatory mechanisms can act as a counterbalance to limit disease severity and protect the host from detrimental effects of an excessive type 1 response.

\section{PPARs Regulate Immune Responses}

Given the role of PPARs in metabolism and adipocyte differentiation, it is intriguing that lipid-activated transcription factors such as PPARs have a role in human immune cell regulation. Initial documentation of PPAR activation in the immune system occurred in 1994 [14]. PPARs were originally described in monocytes and macrophages, neutrophils and peripheral blood lymphocytes. They have since been reported to exist in other immune cell types of hematopoietic origin, including T lymphocytes, B lymphocytes, NK cells, dendritic cells, eosinophils, and mast cells. The extensive expression by many immune cell types suggests that this nuclear receptor may play a very important role in the regulation of immune responses [15-20].

Immune regulation through the activation of PPARs can occur in response to various long chain unsaturated fatty acids generated from the cyclooxygenase and lipoxygenase pathways [21]. The eicosanoid 15-deoxy-Delta ${ }^{12,14}$ prostaglandin $\mathrm{J}_{2}\left(15 \mathrm{~d}-\mathrm{PGJ}_{2}\right)$ produced during arachidonic acid metabolism can activate PPAR $\gamma$ during inflammatory responses. Additional known ligands for include leukotriene B4, 8(S)-hydroxyecosatetraenoic acid (HETE), 15-HETE, and 13-hydroxyoctadecadienoic acid (13-HODE). Both 15HETE and 13-HODE can be produced via the action of 12/15 lipoxygenase. Cytokines through induction of cyclooxygenase and lipoxygenase can regulate the expression and activity of PPAR ; for example, IL-4 induces 12/15 lipoxygenase and production of 15-HETE and 13-HODE whereas IL-13 enhances COX-2 expression and production of $\mathrm{PGE}_{2}$ and $15 \mathrm{~d}-\mathrm{PGJ}_{2}$ [22-24].

PPAR activation is generally known to result in an anti-inflammatory environment and may exert an effect on the immune response by an array of mechanisms $[9$, 25-28]. PPAR $\alpha$ and $\gamma$ exert anti-inflammatory activities through their ability to antagonize other signaling pathways, in part through the interaction with other transcription factors, including $\mathrm{NF} \kappa \mathrm{B}$, activator protein-1 (AP-1), and signal transducers and activators of transcription (STATs). PPAR $\gamma$ agonists inhibit cell-mediated immunity by suppressing the production of inflammatory cytokines like TNF $\alpha$, IL-6, IL-1 $\beta$, and IL-12 [29]. They exhibit suppression on effector mechanisms of classically activated macrophage-inhibiting induction of inducible nitric oxide synthase (iNOS), matrix metalloproteinase-9 (MMP-9), and scavenger receptor A [17]. In mouse thioglycolate-elicited macrophages, PPAR $\gamma$ inhibits recruitment of macrophages to the sites of inflammation by repressing the transcription of monocyte chemoattractant protein-1 (MCP-1) and its receptor CC chemokine receptor 2 (CCR2) in macrophages [29].

With respect to $\mathrm{T}$ cells, PPARs affect activation and effector mechanisms via binding and blocking the action of nuclear factor of activated T cells (NFAT), a transcription factor. Specifically, 13-HODE, an endogenous PPAR $\gamma$ agonist, prevents NFAT association with the IL-2 promoter, thus inhibiting clonal $\mathrm{T}$ cell proliferation [20]. PPAR $\alpha$ has also been shown to repress production of IFN $\gamma$ and IL-17 by $\mathrm{CD} 4^{+} \mathrm{T}$ cells, and PPAR $\gamma$ ligands modulate dendritic cell function to elicit the development of anergic $\mathrm{CD} 4^{+} \mathrm{T}$ cells.

Whereas PPARs downregulate type 1 immunity they upregulate type 2 responses. A study by Dasgupta et al. [30] showed that gemfibrozil, a PPAR $\alpha$ agonist, increases the activity of the transcription factor GATA-3 and inhibits expression of the transcription factor T-box expressed in $\mathrm{T}$ cells (T-bet) to cause increase in IL-4 production by Th2 cells. In a positive feedback manner, IL-4 has also been shown to simultaneously increase the expression of PPAR $y$ and 12,15-lipooxygenase, the enzyme involved in the generation of 13-HODE [22].

\section{Activation of PPARs in Parasitic Infections}

By rendering the host less capable of an inflammatory burst, PPAR activation might favor the establishment of a chronic parasitic infection, making symbiotic survival between host and parasite more likely. Plasmodium falciparum and Schistosoma mansoni infection produce hemozoin, which induces the release of endogenous ligands lipoxin $\mathrm{A}_{4}\left(\mathrm{LXA}_{4}\right), 5,15$ diHETE, and 15-HETE, that can activate PPAR. Production of IL-4 and IL-13 in Leishmania and Toxoplasma infections 
also favors the activation of aaMac whose development is dependent on PPAR $\gamma$.

5.1. Hemozoin. The Plasmodium protozoa are parasites that cause malaria. During disease pathogenesis, rapid growth of merozoites within red blood cells leads to host cell rupture and as the disease progresses, reinvasion of released parasites heigthens parasitemia. As red blood cells and hemoglobin are destroyed, the malaria parasite produces hemozoin, a molecule formed via heme-catalyzed lipoperoxidation as a detoxification product and released together with other cell debris [31].

Plasmodium hemozoin reacts with membrane phospholipids to generate hydroxy-polyunsaturated fatty acids, which are ligands of PPAR $\gamma$. The fact that hemozoin activity is dependent on PPAR $y$ has been demonstrated with the PPAR agonist ciglitizone, the antagonist GW9662, and the PPAR $y$ ligand 15-HETE. Hemozoin has long been known to be a potent modifier of myeloid cells. It modulates phagocytosis, activation by inflammatory cytokines, and generation of the oxidative burst in monocytes. It also inhibits granulocyte-macrophage colony stimulating factor (GM-CSF) and IL-4-mediated differentiation of human monocytes into immature dendritic cells. Furthermore, hemozoin-loaded immature dendritic cells are also unable to differentiate into mature dendritic cells. In these cells, the PPAR $\gamma$ mRNA level increases, whereas the expression of MHC class II, costimulatory molecules CD83, CD80, CD54, CD40, CD1a, and CD83-specific mRNA are lowered [32, 33].

In addition to Plasmodium, the metazoan parasite Schistosoma mansoni, commonly known as blood fluke, also produces hemozoin. The adults of this snail-transmitted parasite feed on red blood cells in humans during part of its life cycle and biomineralizes dimeric heme into an inert crystalline pigment that is structurally identical to Plasmodium falciparum hemozoin. The lipid coat of native schistosome hemozoin is a complex mixture of both neutral lipids and polyunsaturated fatty acids. It can generate, by nonenzymatic catalysis, large amounts of lipoperoxidation products, such as monohydroxy derivatives of arachidonic (HETE) and linoleic (HODE) acid and 4-hydroxynonenal (HNE), which are natural ligands of PPAR. Murine RAW 264.7 macrophage-like cells that have phagocytized schistosomal hemozoin are also decreased in lipopolysaccharidestimulated nitric oxide production [34-36].

Interestingly, the kissing bug Rhodnius prolixus, which is the vector for Trypanosoma cruzi, the etiological agent of Chagas' disease, also crystallizes heme into a dark brown pigment. Since this insect feeds on blood meal, a link may be extrapolated between blood-feeding and hemozoin formation. Production of this PPAR activating molecule can be a strategy commonly acquired by blood feeding parasites and blood taking vectors to suppress host immune response [37].

5.2. Polyunsaturated Fatty Acids (PUFA). The protozoan Toxoplasma gondii infects feline epithelium and grows intracellularly in different mammalian nucleated cells, but it does not feed on or destroy red blood cells and does not produce hemozoin. However, it induces the production of natural ligands for PPAR from platelets. Infection induces platelets to release $\mathrm{LXA}_{4}, 5,15$-diHETE, and 15-HETE at very high levels, two orders of magnitude greater than those used to resolve inflammation [38]. Toxoplasmosis is a chronic disease that is contained by immunity. The disease is only manifested in severely immunocompromised individuals and detrimental to fetus in early gestation. Henderson Jr. and Chi [39] have reported that other PPAR activating lipids, for example, 13-HODE at 10 nanomole concentration has cytotoxicity against the parasite (however, 12-HETE at $1 \mu \mathrm{M}$ does not). Currently, the role of PPAR $y$ in toxoplasmosis remains to be elucidated. However, it is possible for it to have a role in maintaining a balance that supports host and parasite in dormant, chronic infections.

5.3. Interleukin-4. The pivotal role of PPAR $y$ on IL-4 and aaMac-mediated susceptibility has been demonstrated in Leishmania pathogenesis. Leishmaniasis is transmitted by the sandfly vector carrying parasitic protozoa of the genus Leishmania. Clinically the disease can be manifested in three major types, cutaneous, mucocutaneous, and visceral, each caused by different species of the protozoan genus. In the murine model of the cutaneous infection, BALB/c mice, the Leishmania major susceptible strains, have a T helper 2 (Th2) response whereas the $\mathrm{C} 57 \mathrm{BL} / 6$ mice, resistant strains, have a T helper-1 (Th1) response [40]. AaMacs are found in all Th2 cytokine environments. Interestingly, BALB/c mice are more supportive of aaMac maturation than C57BL/6 mice, which are resistant to leishmaniasis [41].

PPAR $y$ expression is strongly associated with maturation of aaMac. Our laboratory investigated visceral leishmaniasis and found that Leishmania donovani induces PPAR $\gamma$ expression in residential macrophages, liver and spleen of BALB/c mice. In addition, oral administration of the PPAR $\gamma$ agonist, curcumin further increases PPAR $\alpha$ and PPAR $\gamma$ expression, and the increase is associated with a heavier parasite burden (Figure 3) [42].

Consistent with our findings, cutaneous Leishmania infection is less severe in mice whose PPAR $\gamma$ gene has been knocked out in their macrophages (Mac-PPAR KO). MacPPAR KO mice had significantly less footpad swelling 57 weeks after injection of $L$. major promastigotes. Lesions in Mac-PPAR KO started to stabilize after 7 weeks, but the footpads of wild type mice continued to enlarge and rapidly underwent necrosis. The loss of PPAR $\gamma$ is associated with loss of aaMac, as cells that express their phenotypic marker, arginase I, are decreased. The production of nitric oxide and IL-6, correspondingly, is increased as well [41].

$\operatorname{PPAR} \gamma$ and PPAR $\delta$ regulate expression of the arginase I gene, a key marker, in aaMac. The PPAR $\gamma$ agonist GW7845 and PPAR $\delta$ agonist GW0742 activate arginase in murine macrophages, and this activation only occurs in wild type macrophages that have PPAR $\gamma$ or PPAR $\delta$, but not in cells where either of their genes has been knocked out [43]. Arginase decreases the amount of arginine, the substrate for NOS to produce nitric oxide. Since intracellular killing of amastigotes requires nitric oxide, both cutaneous and visceral infections are unrestrained in iNOS knockout mice [44-46]. 


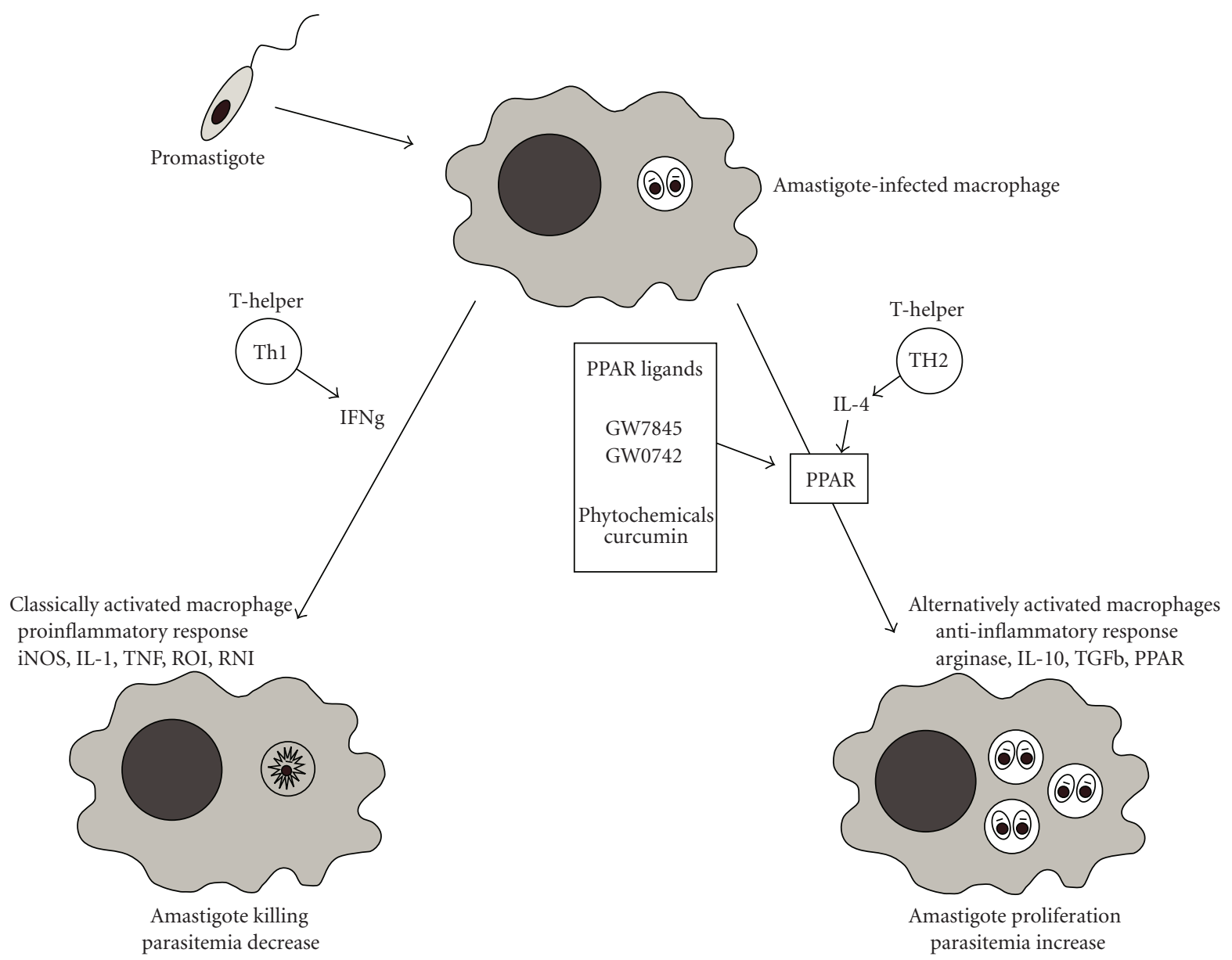

Figure 3: PPAR-mediating suppression of parasiticidal response in leishmaniasis. The sandfly vector carries leishmanial promastigotes to the mammalian host. The parasites then transform into amastigotes within phagolysosomes of host macrophages. Type 1 immunity, with $\mathrm{T}$ helper 1 (Th1) releasing interferon $\gamma$ (IFN $\gamma$ ), leads to classically activated macrophages (caMac). CaMac produce nitric oxide from inducible nitric oxide synthase (iNOS), interleukin-1 (IL-1), tumor necrosis factor (TNF), and reactive oxygen and nitrogen intermediates (ROI, RNI) that act to eliminate the amastigotes. Type 2 immunity, with Th2 releasing IL-4, leads to activation of peroxisome proliferator-activated receptor (PPAR) and alternatively activated macrophages (aaMac). AaMac produce arginase, IL-10, transforming growth factor $\beta$ (TGF $\beta$ ), and PPAR that allow amastigote propagation. PPAR agonists (GW7845 and GW0742) and some phytochemicals (curcumin) can activate PPAR and promote aaMac maturation. Activation of PPAR allows parasite survival as a chronic parasitic infection.

5.4. Interleukin-13. IL-13, another Th2 cytokine that shares a common receptor chain with IL-4, exerts similar effects on macrophages [13]. Functionally, it inhibits the activation of caMac and the production of Th1 cytokines and reactive nitrogen species. The effect of IL-13 is also mediated via the PPAR $\gamma$ pathway. In Toxoplasma-infected macrophages, IL13 activates PPAR by inducing the production of $15 \mathrm{~d}-\mathrm{PGJ}_{2}$. Exogenous addition of PPAR $\gamma$ agonists, rosiglitazone or 15d$\mathrm{PGJ}_{2}$, mimics IL-13 in that it induces CD36, the scavenger receptor whose transcription is turned on by PPAR $\gamma$ [47]. This effect can be further extended to aaMac; IL- $13^{-/-}$mice are incapable of generating cells that express the aaMac phenotype (chitinase-like lectin YM1 or CD20) [48]. CD36 is classified as a class 2 scavenger receptor [49-51]. It is present on the cell surface of many cell types, including monocytes and macrophages. The molecule recognizes oxidized low density lipoprotein (LDL), oxidized phospholipids and lipoproteins, apoptotic cells, and microbial pathogens. With respect to parasites, Plasmodium falciparum erythrocyte membrane protein 1 (PfEMP-1), commonly found in the schizont stage, ring stage and early gametocytes (stage I and IIA), serves as a ligand for CD36. Binding to CD36 is necessary for phagocytosis of P. falciparum-parasitized erythrocytes by human and rodent monocytes/macrophages [52-57]. The function of PPAR $\gamma$ in CD36-mediated phagocytosis is illustrated by the fact that IL-13-induced clearance of the parasitized erythrocytes is blocked by anti-CD36 and GW9662, a PPAR $\gamma$ antagonist [47]. The activity, however, is enhanced by the agonists $15 \mathrm{~d}-\mathrm{PGJ}_{2}$ and ciglitazone [52]. The role of PPAR $y$ in CD36-medited phagocytosis is also confirmed by the observations that mice treated with rosiglitazone have reduced parasitemia of Plasmodium chabaudi, whereas this reduction is not seen in CD36 knockout animals [57]. CD36-mediated phagocytosis will facilitate removal of neutrophils and dead tissues to resolve inflammation as well as clearing of the parasite [52]. Consistent with this 
TABLE 1: Effect of PPAR modulation on the outcome of parasitic infections.

\begin{tabular}{|c|c|c|c|c|c|}
\hline Parasite & Animal model & Treatment & PPAR status & Outcome & Reference \\
\hline \multicolumn{6}{|l|}{$\begin{array}{l}\text { Increase in parasite } \\
\text { load }\end{array}$} \\
\hline Leishmania major & Murine cutaneous leishmaniasis & Gene knockout & $\begin{array}{l}\text { PPAR } \gamma^{-/-} \\
\text {macrophages }\end{array}$ & $\begin{array}{l}\text { Decreased footpad } \\
\text { swelling }\end{array}$ & {$[41]$} \\
\hline Leishmania donovani & Murine visceral leishmaniasis & Curcumin & $\begin{array}{l}\operatorname{PPAR} \gamma \uparrow \\
\operatorname{PPAR} \alpha \uparrow \\
\end{array}$ & $\begin{array}{l}\text { Increased parasite } \\
\text { load }\end{array}$ & {$[42]$} \\
\hline \multicolumn{6}{|l|}{$\begin{array}{l}\text { Decrease in host } \\
\text { tissue damage }\end{array}$} \\
\hline $\begin{array}{l}\text { Schistosoma } \\
\text { japonicum }\end{array}$ & Murine hepatic fibrosis & $\begin{array}{l}\text { Rosiglitazone } \\
\text { (Praziquantel) }\end{array}$ & $\operatorname{PPAR} \gamma \uparrow$ & Decreased fibrosis & {$[60]$} \\
\hline Plasmodium berghei & Murine cerebral malaria & Rosiglitazone & Not stated & Increased survival & {$[57]$} \\
\hline Plasmodium chabaudi & Murine malaria & Rosiglitazone & Not stated & $\begin{array}{l}\text { Decreased } \\
\text { parasitemia }\end{array}$ & {$[57]$} \\
\hline
\end{tabular}

concept that PPAR and aaMac resolve inflammation, Herbert et al. [58] reported that in the absence of IL-4/IL-13-induced aaMac, mice with their macrophage-specific IL-4 receptor knockout (LysMCreIL-4R $\mathrm{R}^{-/ \text {flox }}$ ) die of schistosomiasis. The mutant mice have increased Th1 cytokines and nitric oxide, hepatic and intestinal histopathology due to lack of aaMac to protect against tissue injury. Correspondingly, BALB/c mice with their $\mathrm{T}$ helper-1 responses and immunopathology down-modulated by aaMac survive Schisotsoma mansoni infection better [59].

Henceforth, in sum, studies have revealed that PPAR $\gamma$ suppresses immune reaction to parasitic infection; however, it also plays a role, perhaps through a CD36-dependent manner, in reducing parasitemia as well as resolving inflammation.

\section{Effect of Pharmacological PPAR Ligands on Parasitic Infections}

The anti-inflammatory actions of PPAR $\gamma$ have received great attention because of the availability of synthetic PPAR $\gamma$ activator molecules and their clinical use. The FDA has approved several synthetic PPAR ligands as therapeutic drugs $[59,61]$. For example, clofibrate, an agonist of $\operatorname{PPAR} \alpha$, and its related compounds are used for the treatment of dyslipidemia. Rosiglitazone (drug name Avandia) and pioglitazone (drug name Actos), agonists of PPAR $\gamma$, are used in the management of type 2 diabetes. The drugs improve insulin sensitivity by controlling metabolic and endocrine functions of the adipose tissue. PPARs are attractive drug targets for energy homeostasis and control of lipid and glucose metabolism, as well as possible body weight control. Dual agonists of PPARs have been sought, even though troglitazone and muraglitazar (dual agonist for $\operatorname{PPAR} \alpha / \gamma$ ), originally approved by FDA were later withdrawn due to liver toxicity and increased cardiovascular risks, respectively [62, 63]. PPAR $\gamma$ remains a promising target; safer therapeutics may still become a reality in the future.

Potentially, PPAR ligands may be used in parasitic diseases. To date, in experimental models PPAR ligands have been shown to alleviate host tissue destruction by immune response, as seen in malaria and schistosomiasis. Recently, Lena Serghides and colleagues have shown that rosiglitazone, the PPAR $\gamma$ agonist, is useful in alleviating cerebral malaria in a murine model [57]. Among the variety of symptoms of malaria, cerebral malaria is the deadliest complication that affects an estimated total of 785,000 children in Africa each year. Acutely manifested, the Plasmodium falciparum parasites induce fever, changes in mental status, and coma. The sequestration of parasitized red blood cells (PRBCs) and non-PRBCs in the cerebral capillaries and venules reduces microvascular blood flow and induces hypoxia in the brain. Furthermore, the parasites stimulate the host macrophages to release TNF $\alpha$, IL-1, and uncontrolled production of nitric oxide, which diffuses through the blood-brain barrier and acts on synaptic function, leading to a state of reduced consciousness. Cotreatment of rosiglitazone $(50 \mathrm{mg} / \mathrm{kg}$ of chow) with Plasmodium berghei-parasitized erythrocytes to susceptible mice leads to animal survival.

Similarly, PPAR ligands may be useful in human schistosomiasis, a chronic infection that can cause liver fibrosis. In a murine experimental model of hepatic fibrosis induced by Schistosoma japonicum, Chen and colleagues [60] reported that coadministration of rosiglitazone $(4 \mathrm{mg} / \mathrm{kg})$, daily for 6 weeks (at 4 weeks after infection) with the antischistosomal drug praziquantel $(500 \mathrm{mg} / \mathrm{kg})$ alleviates the symptoms of liver fibrosis. This was demonstrated by a decrease of fibrosis markers, type I and III collagen, and smooth muscle $\alpha$ actin. The decrease in fibrosis is accompanied by reduced binding activity of the transcription factor $\mathrm{NF} \kappa \mathrm{B}$ and lowered levels of TNF $\alpha$ and IL- 6 in the serum. Like cerebral malaria data, these findings also suggest that the PPAR $\gamma$ ligand rosiglitazone may be clinically useful for treatment of liver fibrosis due to schistosomal infection.

\section{Conclusion and Future Prospects}

In conclusion, to date, the role of PPAR $\gamma$ in parasitic diseases remains largely unexplored. Recent evidence suggests that $\operatorname{PPAR} \gamma$ activation may increase replication of parasites as well 
as maintain survival of the host (Table 1). Perhaps it is a measure by which a chronic infection can be established. In a strong cell-mediated immunity, a typical type 1 immune response induces the production of TNF $\alpha$, IFN $\gamma$, and nitric oxide which eliminates parasites. However, the host will severely suffer from tissue destruction during this process, as can be seen in cerebral malaria, when the children may be comatose, and in late stages of visceral leishmaniasis, when the patients may be cachexic and their liver and spleen are enlarged. A type 2 response with IL-4 and IL13 which induces immunosuppressive PPARs would allow the parasites to infect, but spare the host of devastating tissue destruction. In leishmaniasis, for example, activation of PPAR $\gamma$ by curcumin suppresses IFN $\gamma$ and nitric oxide production and increases parasite burden. It may be of interest that curcumin is prevalently used for medicine, cosmetics, and cooking in India, where visceral leishmaniasis is endemic. Perhaps, through PPAR $y$ the host can resolve inflammation and repair tissues to strive for a balance between the host and the parasite that favors mutual survival.

\section{Acknowledgments}

Marion Chan was funded by NIH Grant R01AI45555, R21AR051761 and American Institute for Cancer Research. Kyle W. Evans received stipends from NIH Grant T32AI07101 and Pennsylvania Department of Health (Tobacco Settlement Formula Fund). Dunne Fong was supported by funding from the Department of Defense. We also thank Ms. Grace P. Fong for illustration and graphics.

\section{References}

[1] L. Michalik, J. Auwerx, J. P. Berger, et al., "International union of pharmacology. LXI. Peroxisome proliferator-activated receptors," Pharmacological Reviews, vol. 58, no. 4, pp. 726$741,2006$.

[2] A. Zieleniak, M. Wójcik, and L. A. Woźniak, "Structure and physiological functions of the human peroxisome proliferatoractivated receptor $\gamma$," Archivum Immunologiae et Therapiae Experimentalis, vol. 56, no. 5, pp. 331-345, 2008.

[3] Y. Zhu, C. Qi, J. R. Korenberg, et al., "Structural organization of mouse peroxisome proliferator-activated receptor $\gamma(\operatorname{mPPAR} \gamma)$ gene: alternative promoter use and different splicing yield two mPPAR $\gamma$ isoforms," Proceedings of the National Academy of Sciences of the United States of America, vol. 92, no. 17, pp. 7921-7925, 1995.

[4] H. Sundvold and S. Lien, "Identification of a novel peroxisome proliferator-activated receptor (PPAR) $\gamma$ promoter in man and transactivation by the nuclear receptor ROR $\alpha 1$," Biochemical and Biophysical Research Communications, vol. 287, no. 2, pp. 383-390, 2001.

[5] V. Zoete, A. Grosdidier, and O. Michielin, "Peroxisome proliferator-activated receptor structures: ligand specificity, molecular switch and interactions with regulators," Biochimica et Biophysica Acta, vol. 1771, no. 8, pp. 915-925, 2007.

[6] P. Tontonoz and B. M. Spiegelman, "Fat and beyond: the diverse biology of PPAR $y$," Annual Review of Biochemistry, vol. 77, pp. 289-312, 2008.

[7] J. N. Feige, L. Gelman, L. Michalik, B. Desvergne, and W. Wahli, "From molecular action to physiological outputs: per- oxisome proliferator-activated receptors are nuclear receptors at the crossroads of key cellular functions," Progress in Lipid Research, vol. 45, no. 2, pp. 120-159, 2006.

[8] N. S. Tan, L. Michalik, B. Desvergne, and W. Wahli, "Multiple expression control mechanisms of peroxisome proliferatoractivated receptors and their target genes," Journal of Steroid Biochemistry and Molecular Biology, vol. 93, no. 2-5, pp. 99$105,2005$.

[9] D. S. Straus and C. K. Glass, "Anti-inflammatory actions of PPAR ligands: new insights on cellular and molecular mechanisms," Trends in Immunology, vol. 28, no. 12, pp. 551$558,2007$.

[10] F. O. Martinez, L. Helming, and S. Gordon, "Alternative activation of macrophages: an immunologic functional perspective," Annual Review of Immunology, vol. 27, pp. 451-483, 2009.

[11] J. L. Reyes and L. I. Terrazas, "The divergent roles of alternatively activated macrophages in helminthic infections," Parasite Immunology, vol. 29, no. 12, pp. 609-619, 2007.

[12] G. Raes, A. Beschin, G. H. Ghassabeh, and P. De Baetselier, "Alternatively activated macrophages in protozoan infections," Current Opinion in Immunology, vol. 19, no. 4, pp. 454-459, 2007.

[13] W. Noël, G. Raes, G. H. Ghassabeh, et al., "Alternatively activated macrophages during parasite infections," Trends in Parasitology, vol. 20, no. 3, pp. 126-133, 2004.

[14] S. A. Kliewer, B. M. Forman, B. Blumberg, et al., "Differential expression and activation of a family of murine peroxisome proliferator-activated receptors," Proceedings of the National Academy of Sciences of the United States of America, vol. 91, no. 15, pp. 7355-7359, 1994.

[15] M. E. Greene, B. Blumberg, O. W. McBride, et al., "Isolation of the human peroxisome proliferator activated receptor $\gamma$ cDNA: expression in hematopoietic cells and chromosomal mapping," Gene Expression, vol. 4, no. 4-5, pp. 281-299, 1995.

[16] C. Jiang, A. T. Ting, and B. Seed, "PPAR- $\gamma$ agonists inhibit production of monocyte inflammatory cytokines," Nature, vol. 391, no. 6662, pp. 82-86, 1998.

[17] M. Ricote, J. T. Huang, J. S. Welch, and C. K. Glass, "The peroxisome proliferator-activated receptor $(\operatorname{PPAR} \gamma)$ as a regulator of monocyte/macrophage function," Journal of Leukocyte Biology, vol. 66, no. 5, pp. 733-739, 1999.

[18] L. Széles, D. Töröcsik, and L. Nagy, "PPAR $\gamma$ in immunity and inflammation: cell types and diseases," Biochimica et Biophysica Acta, vol. 1771, no. 8, pp. 1014-1030, 2007.

[19] E. Rigamonti, G. Chinetti-Gbaguidi, and B. Staels, "Regulation of macrophage functions by PPAR- $\alpha$, PPAR- $\gamma$, and LXRs in mice and men," Arteriosclerosis, Thrombosis, and Vascular Biology, vol. 28, no. 6, pp. 1050-1059, 2008.

[20] X. Y. Yang, L. H. Wang, and W. L. Farrar, "A role for PPAR $y$ in the regulation of cytokines in immune cells and cancer," PPAR Research, vol. 2008, Article ID 961753, 12 pages, 2008.

[21] Y. Yang, A. R. Gocke, A. Lovett-Racke, P. D. Drew, and M. K. Racke, "PPAR $\alpha$ regulation of the immune response and autoimmune encephalomyelitis," PPAR Research, vol. 2008, Article ID 546753, 6 pages, 2008.

[22] J. T. Huang, J. S. Welch, M. Ricote, et al., "Interleukin-4dependent production of PPAR- $\gamma$ ligands in macrophages by 12/15-lipoxygenase," Nature, vol. 400, no. 6742, pp. 378-382, 1999.

[23] M.-S. Yang, K.-A. Ji, S.-B. Jeon, et al., "Interleukin-13 enhances cyclooxygenase-2 expression in activated rat brain microglia: implications for death of activated microglia," Journal of Immunology, vol. 177, no. 2, pp. 1323-1329, 2006. 
[24] T. Shimizu, "Lipid mediators in health and disease: enzymes and receptors as therapeutic targets for the regulation of immunity and inflammation," Annual Review of Pharmacology and Toxicology, vol. 49, pp. 123-150, 2009.

[25] R. B. Clark, "The role of PPARs in inflammation and immunity," Journal of Leukocyte Biology, vol. 71, no. 3, pp. 388400, 2002.

[26] R. A. Daynes and D. C. Jones, "Emerging roles of PPARs in inflammation and immunity," Nature Reviews Immunology, vol. 2, no. 10, pp. 748-759, 2002.

[27] A. Castrillo and P. Tontonoz, "Nuclear receptors in macrophage biology: at the crossroads of lipid metabolism and inflammation," Annual Review of Cell and Developmental Biology, vol. 20, pp. 455-480, 2004.

[28] S. J. Bensinger and P. Tontonoz, "Integration of metabolism and inflammation by lipid-activated nuclear receptors," Nature, vol. 454, no. 7203, pp. 470-477, 2008.

[29] A. Szanto and L. Nagy, "The many faces of PPARy: antiinflammatory by any means?" Immunobiology, vol. 213, no. 9-10, pp. 789-803, 2008.

[30] S. Dasgupta, A. Roy, M. Jana, D. M. Hartley, and K. Pahan, "Gemfibrozil ameliorates relapsing-remitting experimental autoimmune encephalomyelitis independent of peroxisome proliferator-activated receptor- $\alpha$," Molecular Pharmacology, vol. 72, no. 4, pp. 934-946, 2007.

[31] T. Hänscheid, T. J. Egan, and M. P. Grobusch, "Haemozoin: from melatonin pigment to drug target, diagnostic tool, and immune modulator," Lancet Infectious Diseases, vol. 7, no. 10, pp. 675-685, 2007.

[32] O. A. Skorokhod, M. Alessio, B. Mordmüller, P. Arese, and E. Schwarzer, "Hemozoin (malarial pigment) inhibits differentiation and maturation of human monocyte-derived dendritic cells: a peroxisome proliferator-activated receptor$\gamma$-mediated effect," Journal of Immunology, vol. 173, no. 6, pp. 4066-4074, 2004.

[33] B. C. Urban and S. Todryk, "Malaria pigment paralyzes dendritic cells," Journal of Biology, vol. 5, no. 2, article 4, 2006.

[34] M. M. Chen, L. Shi, and D. J. Sullivan Jr., "Haemoproteus and Schistosoma synthesize heme polymers similar to Plasmodium hemozoin and $\beta$-hematin," Molecular and Biochemical Parasitology, vol. 113, no. 1, pp. 1-8, 2001.

[35] M. F. Oliveira, S. W. Kycia, A. Gomez, et al., "Structural and morphological characterization of hemozoin produced by Schistosoma mansoni and Rhodnius prolixus," FEBS Letters, vol. 579, no. 27, pp. 6010-6016, 2005.

[36] M. D. Carter, S. Reese Harry, and D. W. Wright, "Identification of hydroxyeicosatetraenoic acid components of schistosomal hemozoin," Biochemical and Biophysical Research Communications, vol. 363, no. 3, pp. 867-872, 2007.

[37] T. J. Egan, "Haemozoin formation," Molecular and Biochemical Parasitology, vol. 157, no. 2, pp. 127-136, 2008.

[38] G. L. Bannenberg, J. Aliberti, S. Hong, A. Sher, and C. Serhan, "Exogenous pathogen and plant 15-lipoxygenase initiate endogenous lipoxin A4 biosynthesis," Journal of Experimental Medicine, vol. 199, no. 4, pp. 515-523, 2004.

[39] W. R. Henderson Jr. and E. Y. Chi, "Cytotoxic activity of 13-hydroxyoctadecadienoic acid against Toxoplasma gondii," Parasitology, vol. 105, no. 3, pp. 343-347, 1992.

[40] D. Sacks and N. Noben-Trauth, "The immunology of susceptibility and resistance to Leishmania major in mice," Nature Reviews Immunology, vol. 2, no. 11, pp. 845-858, 2002.

[41] J. I. Odegaard, R. R. Ricardo-Gonzalez, and M. H. Goforth, "Macrophage-specific PPAR $\gamma$ controls alternative activation and improves insulin resistance," Nature, vol. 447, no. 7148, pp. 1116-1120, 2007.

[42] N. Adapala and M. M. Chan, "Long-term use of an antiinflammatory, curcumin, suppressed type 1 immunity and exacerbated visceral leishmaniasis in a chronic experimental model," Laboratory Investigation, vol. 88, no. 12, pp. 13291339, 2008.

[43] A. Gallardo-Soler, C. Gómez-Nieto, M. L. Campo, et al., "Arginase I induction by modified lipoproteins in macrophages: a peroxisome proliferator-activated receptor$\gamma / \delta$-mediated effect that links lipid metabolism and immunity," Molecular Endocrinology, vol. 22, no. 6, pp. 1394-1402, 2008.

[44] X.-Q. Wei, I. G. Charles, A. Smith, et al., "Altered immune responses in mice lacking inducible nitric oxide synthase," Nature, vol. 375, no. 6530, pp. 408-411, 1995.

[45] H. W. Murray and F. Nathan, "Macrophage microbicidal mechanisms in vivo: reactive nitrogen versus oxygen intermediates in the killing of intracellular visceral Leishmania donovani," Journal of Experimental Medicine, vol. 189, no. 4, pp. 741-746, 1999.

[46] M. M. Chan, N. S. Adapala, and D. Fong, "Curcumin overcomes the inhibitory effect of nitric oxide on Leishmania," Parasitology Research, vol. 96, no. 1, pp. 49-56, 2005.

[47] A. Berry, P. Balard, A. Coste, et al., "IL-13 induces expression of CD36 in human monocytes through PPAR $\gamma$ activation," European Journal of Immunology, vol. 36, no. 6, pp. 1642-1652, 2007.

[48] A. Nencioni, F. Grunebach, A. Zobywlaski, C. Denzlinger, W. Brugger, and P. Brossart, "Dendritic cell immunogenicity is regulated by peroxisome proliferator-activated receptor $\gamma$," Journal of Immunology, vol. 169, no. 3, pp. 1228-1235, 2002.

[49] L. Serghides, T. G. Smith, S. N. Patel, and K. C. Kain, "CD36 and malaria: friends or foes?" Trends in Parasitology, vol. 19, no. 10, pp. 461-469, 2003.

[50] T. Areschoug and S. Gordon, "Scavenger receptors: role in innate immunity and microbial pathogenesis," Cellular Microbiology, vol. 11, no. 8, pp. 1160-1169, 2009.

[51] R. L. Silverstein and M. Febbraio, "CD36, a scavenger receptor involved in immunity, metabolism, angiogenesis, and behavior," Science Signaling, vol. 2, no. 72, 2009.

[52] L. Serghides and K. C. Kain, "Peroxisome proliferatoractivated receptor $\gamma$-retinoid $\mathrm{X}$ receptor agonists increase CD36-dependent phagocytosis of Plasmodium falciparumparasitized erythrocytes and decrease malaria-induced TNF $\alpha$ secretion by monocytes/macrophages," Journal of Immunology, vol. 166, no. 11, pp. 6742-6748, 2001.

[53] T. G. Smith, L. Serghides, S. N. Patel, M. Febbraio, R. L. Silverstein, and K. C. Kain, "CD36-mediated nonopsonic phagocytosis of erythrocytes infected with stage I and IIA gametocytes of Plasmodium falciparum," Infection and Immunity, vol. 71, no. 1, pp. 393-400, 2003.

[54] S. N. Patel, L. Serghides, T. G. Smith, et al., "CD36 mediates the phagocytosis of Plasmodium falciparum-infected erythrocytes by rodent macrophages," Journal of Infectious Diseases, vol. 189, no. 2, pp. 204-213, 2004.

[55] K. Ayi, S. N. Patel, L. Serghides, T. G. Smith, and K. C. Kain, "Nonopsonic phagocytosis of erythrocytes infected with ringstage Plasmodium falciparum," Infection and Immunity, vol. 73, no. 4, pp. 2559-2563, 2005.

[56] L. Serghides and K. C. Kain, "Peroxisome proliferatoractivated receptor $\gamma$ and retinoid $\mathrm{X}$ receptor agonists have minimal effects on the interaction of endothelial cells with 
Plasmodium falciparum-infected erythrocytes," Infection and Immunity, vol. 73, no. 2, pp. 1209-1213, 2005.

[57] L. Serghides, S. N. Patel, K. Ayi, et al., "Rosiglitazone modulates the innate immune response to Plasmodium falciparum infection and improves outcome in experimental cerebral malaria," Journal of Infectious Diseases, vol. 199, no. 10, pp. 1536-1545, 2009.

[58] D. R. Herbert, C. Hölscher, M. Mohrs, et al., "Alternative macrophage activation is essential for survival during schistosomiasis and downmodulates $\mathrm{T}$ helper 1 responses and immunopathology," Immunity, vol. 20, no. 5, pp. 623-635, 2004.

[59] P. Gervois, J. C. Fruchart, and B. Staels, "Drug insight: mechanisms of action and therapeutic applications for agonists of peroxisome proliferator-activated receptors," Nature Clinical Practice Endocrinology and Metabolism, vol. 3, no. 2, pp. 145156, 2007.

[60] H. Chen, Y. W. He, W. Q. Liu, and J. H. Zhang, "Rosiglitazone prevents murine hepatic fibrosis induced by Schistosoma japonicum," World Journal of Gastroenterology, vol. 14, no. 18, pp. 2905-2911, 2008.

[61] F. Ondrey, "Peroxisome proliferator-activated receptor $\gamma$ pathway targeting in carcinogenesis: implications for chemoprevention," Clinical Cancer Research, vol. 15, no. 1, pp. 2-8, 2009.

[62] P. Balakumar, M. Rose, S. S. Ganti, et al., "PPAR dual agonists: are they opening Pandora's box?" Pharmacological Research, vol. 56, no. 2, pp. 91-98, 2007.

[63] A. Rubenstrunk, R. Hanf, D. W. Hum, J.-C. Fruchart, and B. Staels, "Safety issues and prospects for future generations of PPAR modulators," Biochimica et Biophysica Acta, vol. 1771, no. 8, pp. 1065-1081, 2007. 

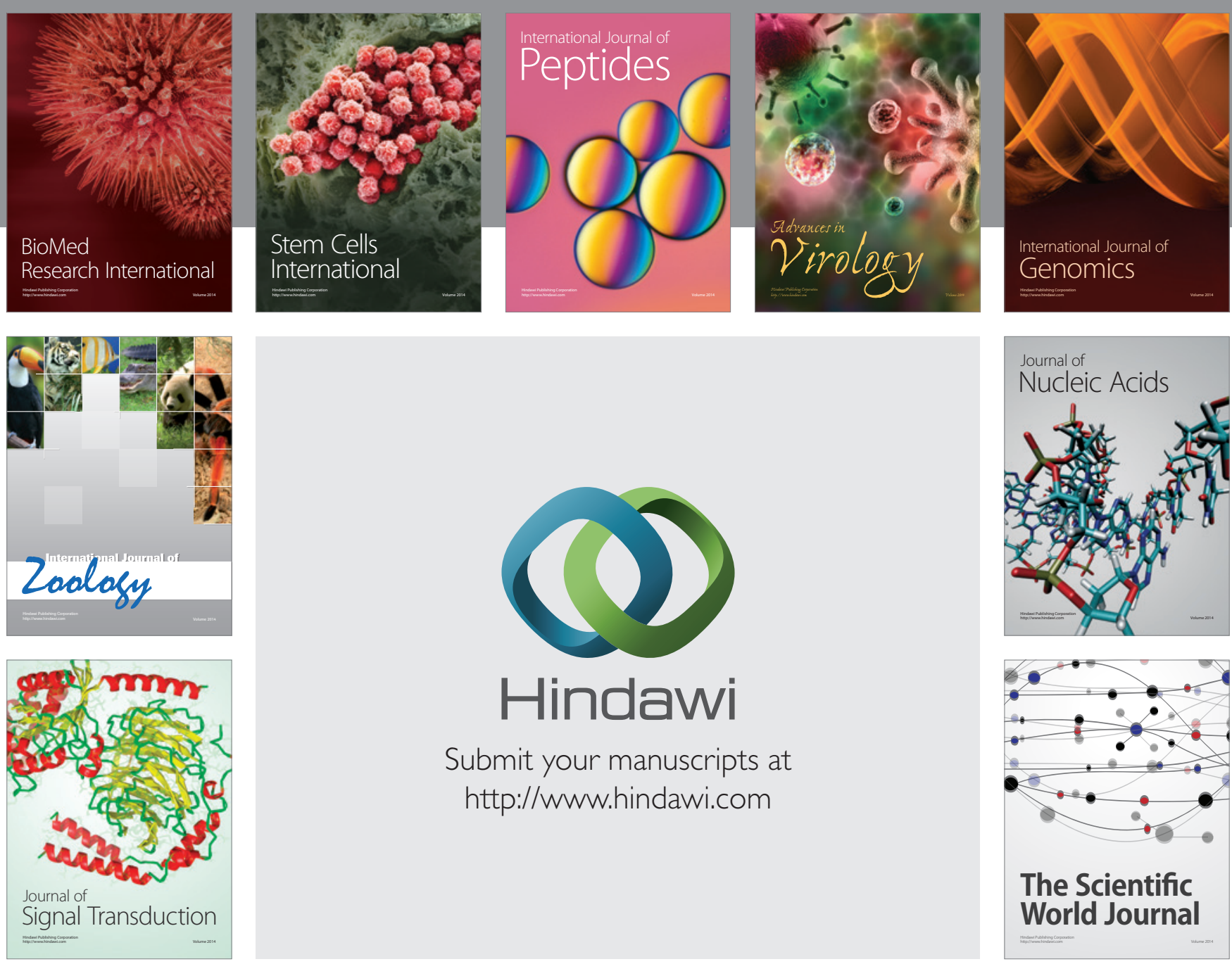

Submit your manuscripts at

http://www.hindawi.com
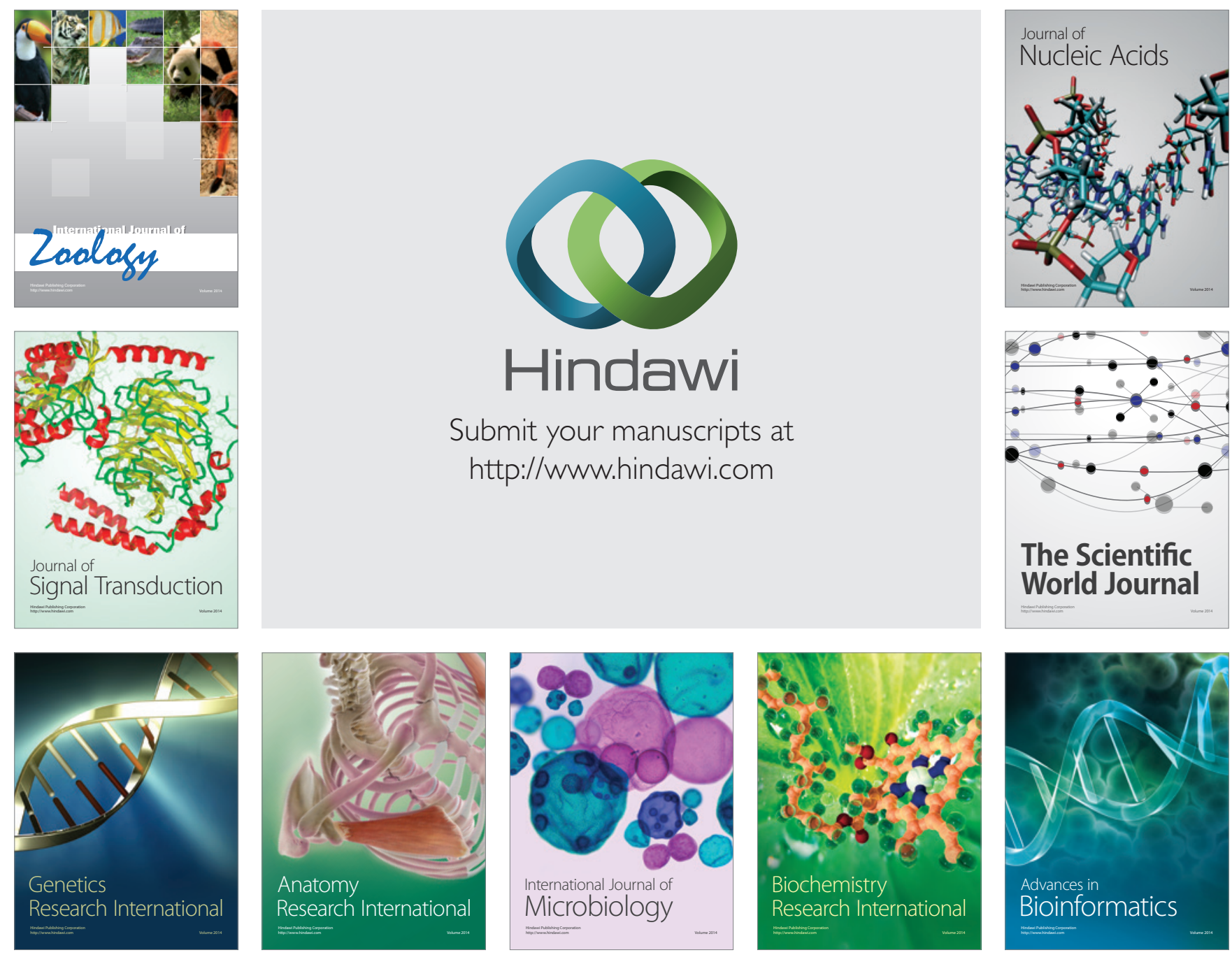

The Scientific World Journal
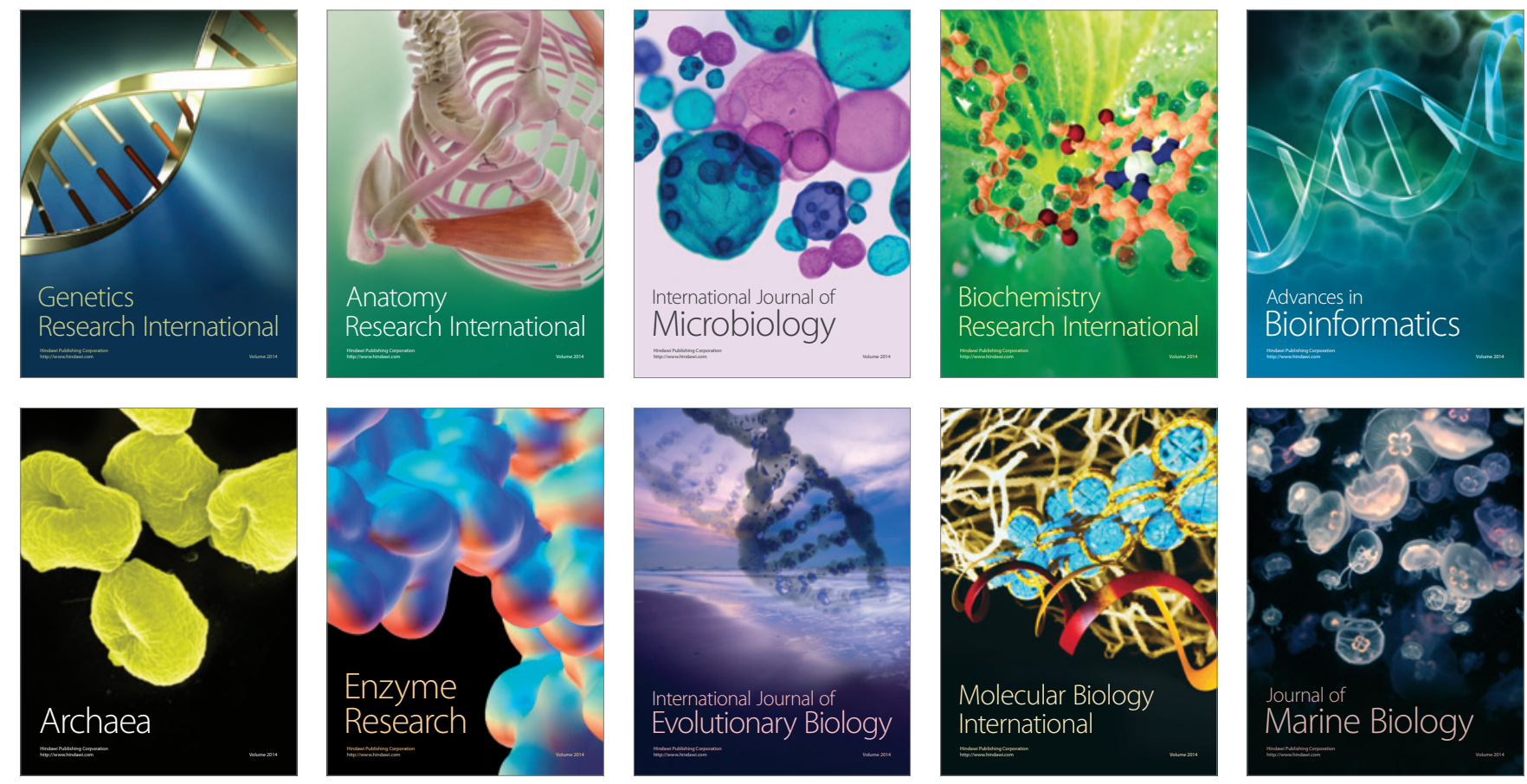